\title{
CODA Q estimates for Kumaun Himalaya
}

\author{
A Paul*, S C Gupta** and Charu C Pant* \\ *Department of Geology, Kumaun University, Nainital 263 002, India. \\ ** Department of Earthquake Engineering, Indian Institute of Technology Roorkee, Roorkee 247 667, India.
}

Coda $Q\left(Q_{c}\right)$ estimates for the Kumaun Himalaya region have been obtained in high frequency range. Local earthquakes, recorded by a digital seismic network in the region, which fall in the epicentral distances range of 10 to $80 \mathrm{~km}$ and with a local magnitude range of 1.4 to 2.8 , have been used. The coda waves of $30 \mathrm{sec}$ window length, filtered at seven frequency bands centered at 1.5, $3,6,9,12,18$ and $24 \mathrm{~Hz}$, have been analysed using the single backscattering model. The values of $Q_{c}$ estimates vary from 65 to 283 at $1.5 \mathrm{~Hz}$ to 2119 to 3279 at $24.0 \mathrm{~Hz}$ which showed that $Q_{c}$ is frequency dependent and its value increases as frequency increases.

A frequency-dependent $Q_{c}$ relationship, $Q_{c}=(92 \pm 4.73) f^{(1.07 \pm .023)}$, is obtained for the region representing the average attenuation characteristics of seismic waves for Kumaun Himalaya region.

\section{Introduction}

The study of attenuation in high frequency seismic waves $(1-25 \mathrm{~Hz})$ is useful for both the seismologist and the earthquake engineer as it is an essential parameter in predicting the earthquake ground motion in seismic hazard analysis. Usually, seismic wave attenuation is determined from the analysis of direct waves ( $P \& S$-wave), surface waves and coda waves. However, in most studies the decay of coda waves of local earthquakes, characterized by Coda $Q$ or $Q_{c}$, is used to measure the attenuation in the earth's crust. The single backscattering model given by Aki and Chouet (1975) is used to analyse the coda wave of local earthquakes. According to this model the coda waves of local earthquakes recorded within $100 \mathrm{~km}$ of epicentral distance are considered as the superposition of backscattered body waves ( $S$-waves) scattered due to numerous heterogeneities present in the earth's crust and upper mantle. Therefore, coda waves provide the average information of the medium instead of the information about the single path connected from source to receiver.

A number of seismic wave attenuation studies, in India as well as in other parts of the world, have been carried out using the coda waves part of local earthquakes employing the single backscattering model (Roecker et al 1982; Pulli 1984; Woodgold 1994, Gupta et al 1995; Gupta 1999). In India, the data of both local earthquakes (weak motion as well as strong motion records) from the Garhwal Himalaya region have been used to carry out seismic wave attenuation studies.

The region of Kumaun Himalaya is seismically active. To record the local earthquake activity in the region a five-station digital telemetered network was deployed in 1999. This network recorded data of local earthquakes that occurred in the region which provided the opportunity to study seismic-wave attenuation characteristics in high frequency range $(1-25 \mathrm{~Hz})$. No such study has been carried out so far in the Kumaun Himalaya region.

\section{Data set and analysis}

The five-station digital telemetered seismic network (DTSN), operational since 1999, records the local, regional and high magnitude teleseismic activity. The network was deployed by the Department of Geology, Kumaun University, Nainital under a Department of Science and Technology (DST) funded project. It comprises of four remote

Keywords. $Q_{c}$; coda waves; single backscattering model; digital telemetered seismic network; Kumaun Himalaya.

Proc. Indian Acad. Sci. (Earth Planet. Sci.), 112, No. 4, December 2003, pp. 569-576

(C) Printed in India. 


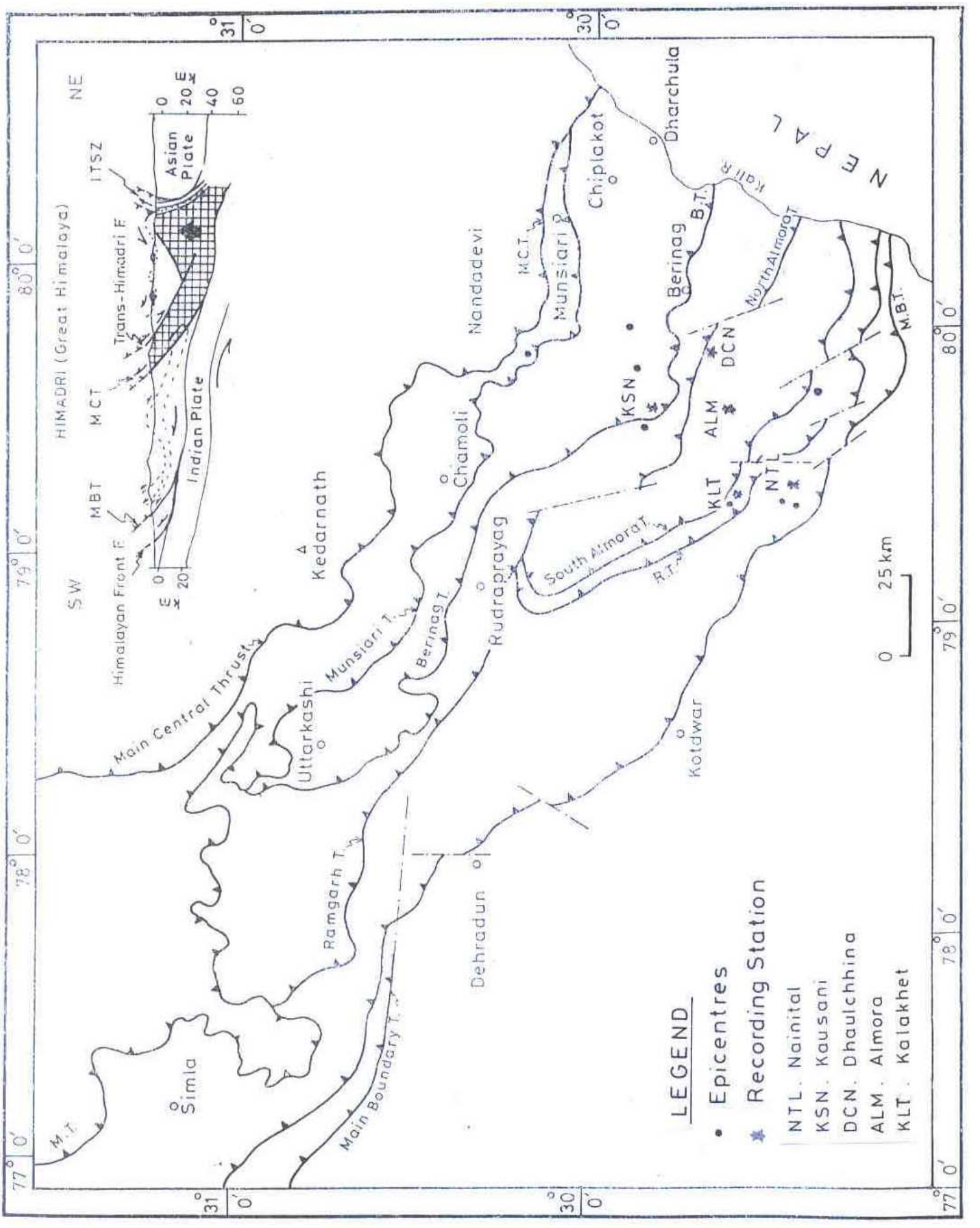


Table 1. Hypo central parameters of the events considered in this study.

\begin{tabular}{|c|c|c|c|c|c|c|}
\hline $\begin{array}{l}\text { Sl. } \\
\text { No }\end{array}$ & $\begin{array}{c}\text { Date } \\
\mathrm{Yr} / \mathrm{Mn} / \mathrm{D}\end{array}$ & $\begin{array}{l}\text { Origin time } \\
\quad \text { (IST) } \\
\mathrm{Hr} / \mathrm{Mn} / \mathrm{Sec}\end{array}$ & $\begin{array}{l}\text { Latitude } \\
\left({ }^{\circ} \mathrm{N}\right)\end{array}$ & $\begin{array}{l}\text { Longitude } \\
\qquad\left({ }^{\circ} \mathrm{E}\right)\end{array}$ & $\begin{array}{c}\text { Mag. } \\
M_{L}\end{array}$ & $\begin{array}{c}\text { Focal } \\
\text { Depth } \\
(\mathrm{km})\end{array}$ \\
\hline 1. & $\begin{array}{lll}99 & 09 & 22\end{array}$ & $\begin{array}{lll}22 & 27 & 30.68\end{array}$ & 29.94 & 80.06 & 1.7 & 1.8 \\
\hline 2. & $\begin{array}{lll}99 & 09 & 23\end{array}$ & $\begin{array}{lll}15 & 12 & 48.82\end{array}$ & 29.90 & 79.97 & 2.8 & 1.2 \\
\hline 3. & $\begin{array}{lll}99 & 12 & 18\end{array}$ & $\begin{array}{lll}05 & 25 & 06.67\end{array}$ & 29.88 & 79.72 & 1.7 & 8.8 \\
\hline 4. & $\begin{array}{lll}01 & 01 & 24\end{array}$ & $14 \quad 38 \quad 43.50$ & 29.62 & 79.41 & 2.0 & 6.8 \\
\hline 5. & $\begin{array}{lll}01 & 03 & 03\end{array}$ & $\begin{array}{lll}20 & 07 & 09.40\end{array}$ & 30.19 & 79.91 & 2.7 & 2.85 \\
\hline 6. & $\begin{array}{lll}01 & 04 & 04 \\
\end{array}$ & $\begin{array}{lll}07 & 44 & 48.82\end{array}$ & 29.41 & 79.79 & 1.6 & 3.83 \\
\hline 7. & $\begin{array}{lll}01 & 05 & 05\end{array}$ & $\begin{array}{lll}18 & 30 & 58.06\end{array}$ & 29.43 & 79.40 & 1.7 & 0.97 \\
\hline 8. & $\begin{array}{lll}01 & 05 & 08\end{array}$ & $\begin{array}{lll}15 & 06 & 29.04\end{array}$ & 29.46 & 79.42 & 1.4 & 0.85 \\
\hline
\end{tabular}

stations and a central recording station (CRS) situated at Nainital. Each remote station and CRS comprises of a short period three component seismometer to generate the velocity time history of ground motion in digital form at a sampling rate of 100 samples/sec. The digital data from the remote stations are transmitted to the CRS. An accelerometer is also co-located at CRS. The locations of the remote stations and CRS are shown on the tectonic map of the region (figure 1).

Eight local earthquakes in digital form recorded within $100 \mathrm{~km}$ of epicentral distance are used in this study (figure 1, table 1). These earthquakes have been located by the data acquired through the five station DTSN. The coda waves of $30 \mathrm{sec}$ duration, observed on all the event-station pairs, have been analysed. The $30 \mathrm{sec}$ window is sufficient to check the decay pattern of coda waves in the present study (figure 2a). However, the coda window can increase or decrease as per the available data set. The quality factor of the coda waves $\left(Q_{c}\right)$ has been estimated at seven frequency bands (table 2) for the Kumaun region adopting the single backscattering model (Aki and Chouet 1975). The bandwidth of $0.67 f$ ( $f$ is central frequency) has been used in the present study to filter the coda waves using the Butterworth bandpass filter.

\section{Geology and tectonics of the region}

The Himalaya, representing one of the most active orogens of the world produced as a consequence of collision of the Indian and Asian continental plates is seismotectonically active. The northward movement of the Indian lithospheric plate and collision with the Eurasian plate is evident by the complicated folding, thrusting in the belt and reversals of magnetic polarity on the floor of the Indian Ocean (Molnar and Tapponnier 1975; Powell 1979; Malinconico 1989). The main collision which started in Eocene (40-50 Ma) has resulted in closure of approximately $2000 \mathrm{~km}$ between the two plates (Molnar and Tapponnier 1975). The Kumaun sector manifests strong deformation and reactivation of some of the faults and thrusts during Quaternary times. This is amply evident by the recurrent seismicity patterns, geomorphic developments and by geodetic surveys (Valdiya 1999).

The Uttaranchal Himalaya shows development of all the four morpho-tectonic zones which are demarcated by intracrustal boundary thrust of regional dimension. These zones from south to north are

- Siwalik or Sub-Himalaya

- Lesser Himalaya

- Great Himalaya

- Tethys Himalaya.

The Sub-Himalaya comprising molasse of Middle Miocene to Upper Pliestocene age being delimited by the Himalayan Frontal Fault (HFF) in the south and Main Boundary Thrust (MBT) in the north. The Lesser Himalaya, comprising various thrust sheets and nappes being sandwiched between the Main Bounday Thrust and Main Central Thrust (MCT) at the base of great Himalaya. In general, the Lesser Himalayan Precambrian sedimentary succession is covered by vast low to medium grade metamorphic thrust sheets of Ramgarh and Almora groups. The great Himalaya comprises kyanite-sillimanite bearing high grade psammatic gneisses and schist intruded by anatectic Tertiary leucogranites. As a matter of fact, these rocks constitute the foundation of the Tethyian sedimentary pile of Proterozoic to Upper Cretaceous/Eocene age. The northern margin of the Tethyian sequence is marked by the Indus-Tsangpo Suture Zone representing the fossil subduction zone with ophiolitis and deep sea sediments. It is significant to note that the basement rocks of the Lesser Himalaya are not exposed. The Amritpur Granite (1800 \pm $50 \mathrm{Ma}$ ) exposed near the MBT might constitute the 

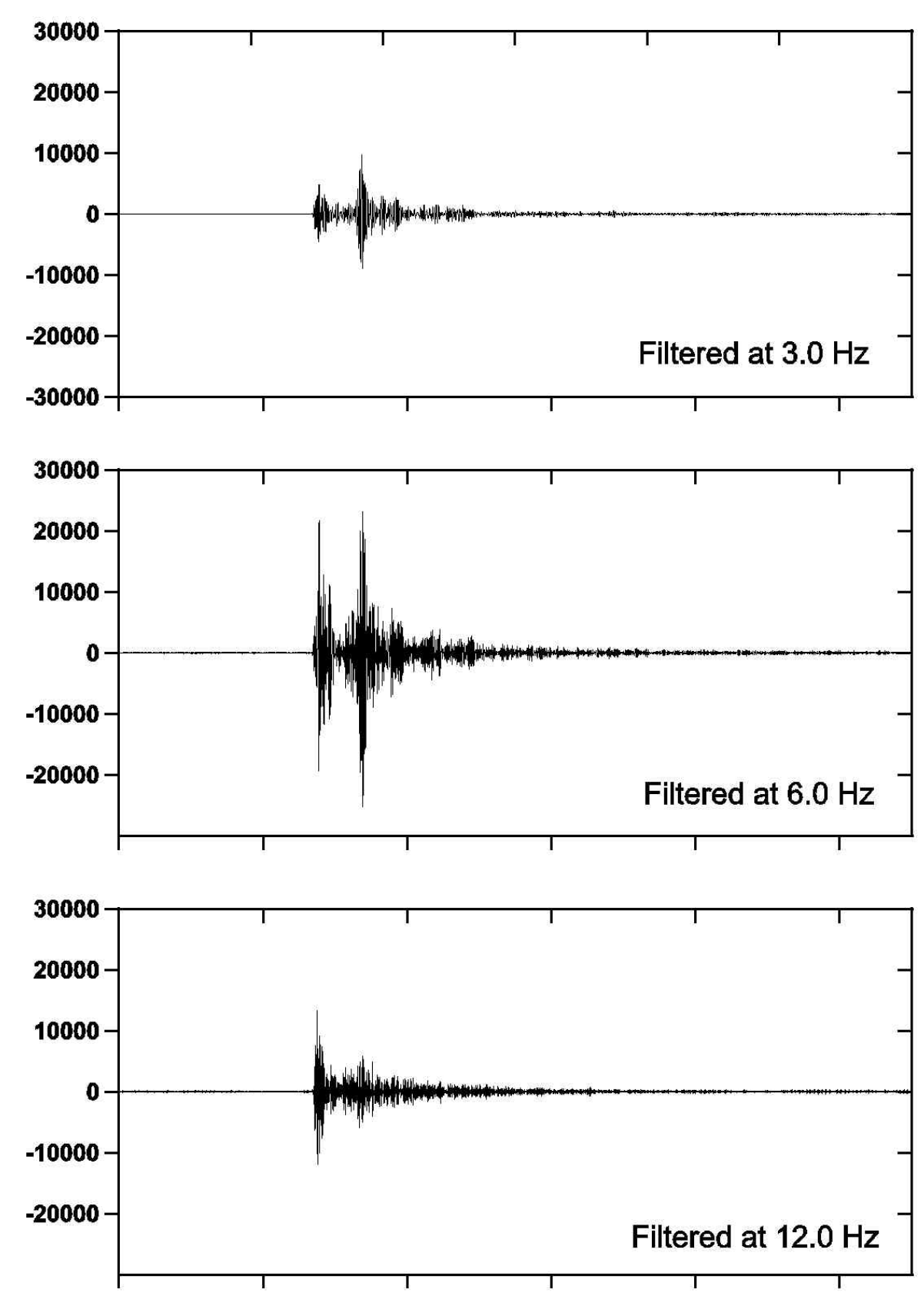

Figure 2(a). (Continued)

basement (Valdiya 1995). The recording stations of the network, epicentral locations of the events and generalized tectonic framework of Uttaranchal Himalaya are shown in figure 1.

\section{Method}

In the single backscattering model, the coda waves amplitudes, $A(f, t)$, for a narrow bandwidth signal centered at frequency $f$ and at lapse time $t$ (measured from earthquake origin time), is described as, $A(f, t)=S(f) t^{-a} \exp \left(-\pi f t / Q_{c}\right)$, where $S(f)$ represents the source function at frequency $f$ and is considered as constant, $a$ is the geometrical spreading factor and taken as unity for body waves, and $Q_{c}$ is the quality factor representing the average attenuation characteristics of the medium. After rewriting the above equation in linear form, as $\ln [A(f, t) t]=C-b t$, where $C=\ln S(f)$ and slope, $b=\pi f / Q_{c}, Q_{c}$, can be obtained at different frequency $f$ from the slope $(=b)$ of the equation. Here, lapse time ' $t$ ' is taken as twice the $S$-wave travel time. As the coda waves are backscattered $S$-waves and are considered to be recorded after the arrival of all direct phases (Rautian and Khalturin 1978). To estimate $Q_{c}$-value at different frequency bands, the coda waves are filtered at seven 

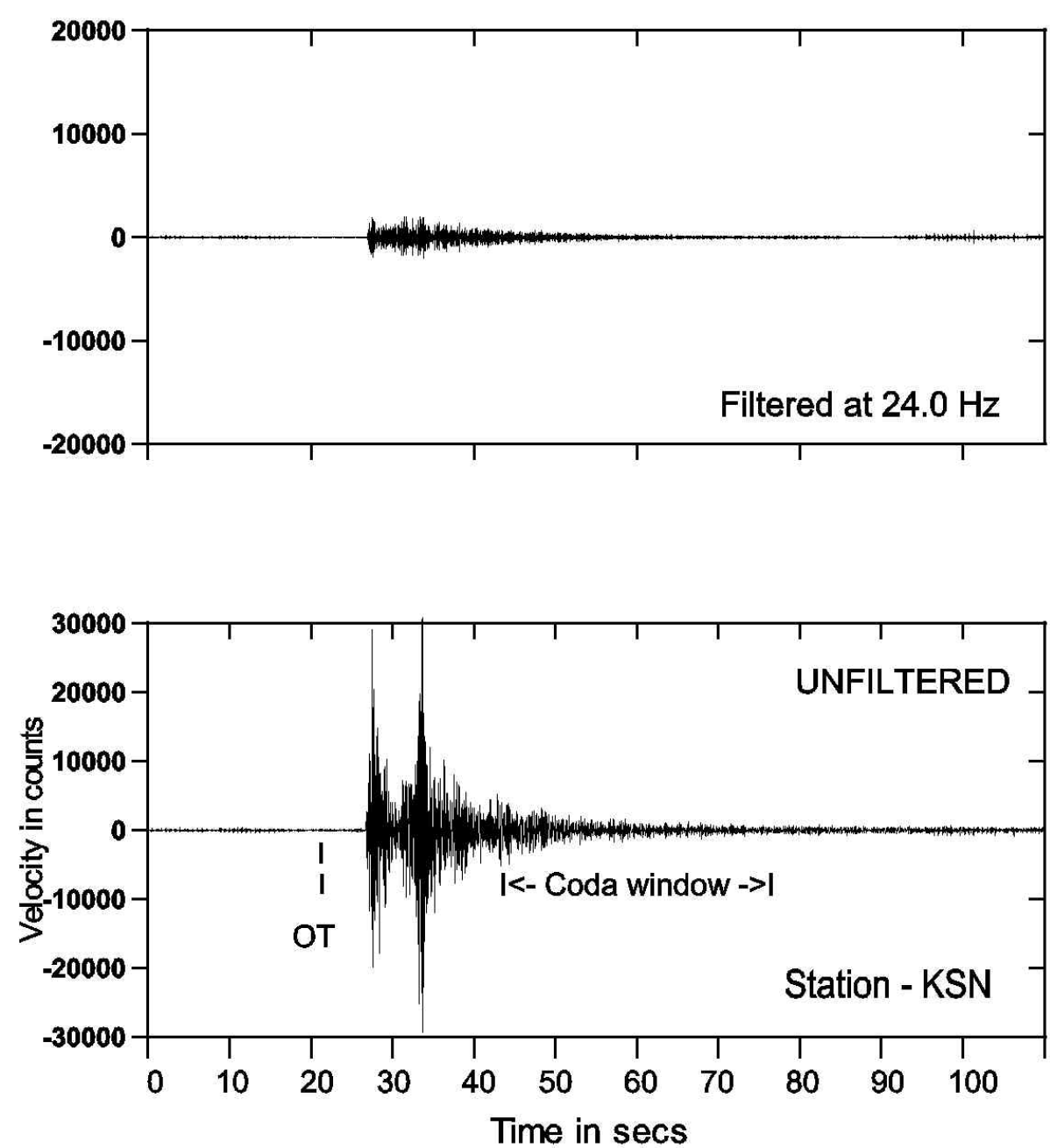

Figure 2. (a) Unfiltered and filtered seismogram recorded at Kausani station on 23/09/1999.

frequency bands. An example of unfiltered and filtered seismograms recorded at Kausani station on $23 / 9 / 99$, the slope of linear equation fitted between logarithmic coda amplitudes and lapse time and the $Q_{c}$ values obtained at these frequency bands are shown in figure 2 ( $a$ and $b$ ).

\section{Results and discussion}

$Q_{c}$ estimates, at seven frequency bands viz., 1.5, $3,6,9,12,18$ and $24 \mathrm{~Hz}$, have been derived in Kumaun Himalaya using the coda waves of $30 \mathrm{sec}$ window length. $30 \mathrm{sec}$ coda window from $22-$ stations of 8 events have been used for estimation of $Q_{c}$. Only those $Q_{c}$-values which fulfill the criteria of having correlation coefficient, between log of coda amplitude $\ln A(f, t)$ and lapse time $t, 75 \%$ or more are considered for analysis and interpretation. There are 122 such $Q_{c}$-values which vary from 65 to 283 at $1.5 \mathrm{~Hz}$ and 2119 to 3279 at $24 \mathrm{~Hz}$. These values are plotted, as a function of frequency, in figure 3(a) and their mean value is computed at each frequency. These values are listed in table 3 and plotted as a function of frequency in figure 3(b). Both figures 3 ( $\mathrm{a}$ and $\mathrm{b}$ ) demonstrate that $Q_{c}$ is frequency dependent and its value increases as frequency increases. Using this data set a frequencydependent $Q_{c}$ relationship in the form of power law, $Q_{c}=(92 \pm 4.73) f^{(1.07 \pm .023)}$, is obtained for the region which represents the average attenuation characteristics for the Kumaun and surrounding region.

Although, the present study is based on limited data set, still the attenuation relationship, $Q_{c}=(92 \pm 4.73) f^{(1.07 \pm .023)}$, provides first hand information on seismic wave attenuation characteristics of Kumaun Himalaya region. There is a scope of refinement of $Q_{c}$ by considering the larger data set of local earthquakes.

The study of frequency dependence coda $Q$ is interpreted as a tectonic parameter and regions of high tectonic activity are characterized by low 

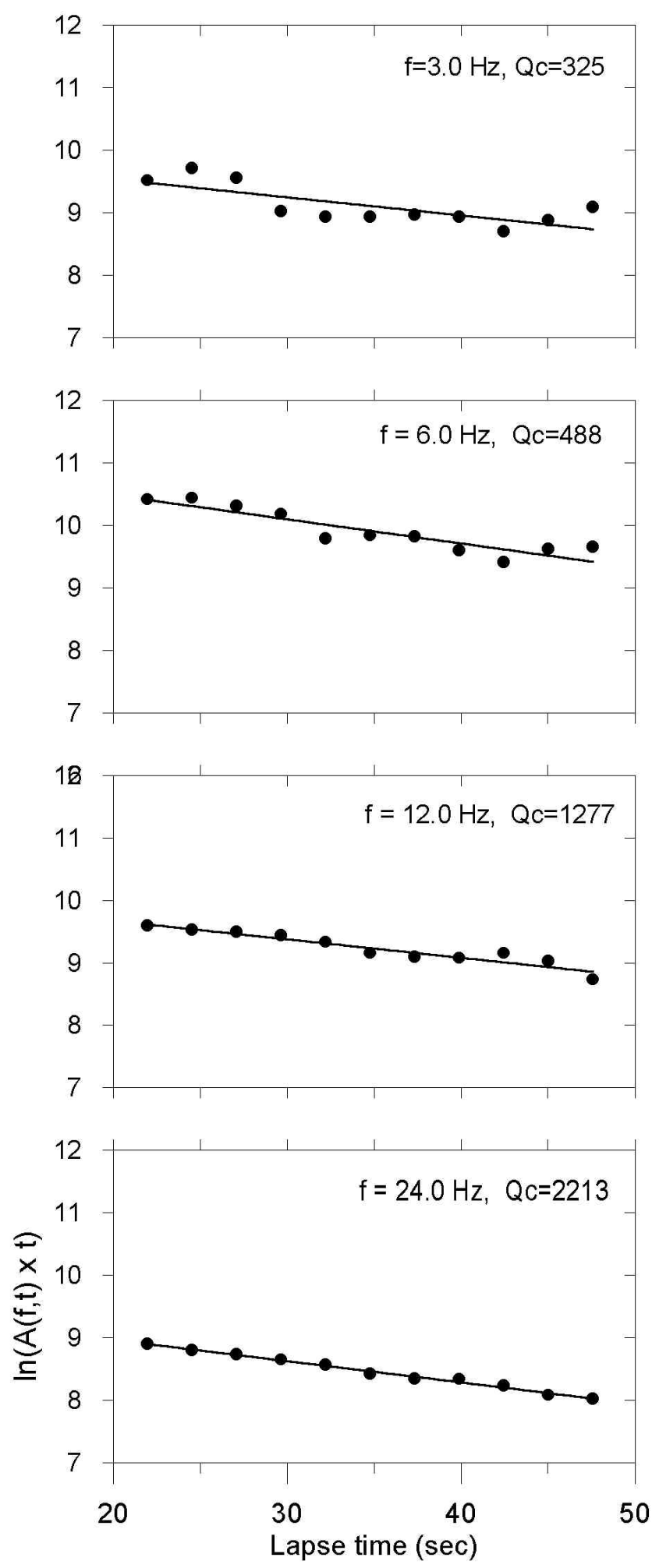

Figure 2. (b) Slope of linear equation fitted between logarithmic coda amplitudes and lapse time.

$Q_{c}$ compared to stable regions where $Q_{c}$ is high. Further, the frequency dependent $Q_{c}$-relationship, in the form of $Q_{c}=Q_{0} f^{n}$, generally provides $Q_{0}$ $\left(Q_{c}\right.$ at $\left.1 \mathrm{~Hz}\right)$ which represents the level of medium heterogeneities and $n$, power of frequency depen-
Table 2. Parameters of Butterworth band pass filter used for filtering the local earthquake data.

\begin{tabular}{ccc}
\hline $\begin{array}{c}\text { Low cutoff } \\
(\mathrm{Hz})\end{array}$ & $\begin{array}{c}\text { Central frequency }\left(f_{c}\right) \\
(\mathrm{Hz})\end{array}$ & $\begin{array}{c}\text { High cutoff } \\
(\mathrm{Hz})\end{array}$ \\
\hline 1.0 & 1.5 & 2.0 \\
\hline 2.0 & 3.0 & 4.0 \\
\hline 4.0 & 6.0 & 8.0 \\
\hline 6.0 & 9.0 & 12.0 \\
\hline 8.0 & 12.0 & 16.0 \\
\hline 12.0 & 18.0 & 24.0 \\
\hline 16.0 & 24.0 & 32.0 \\
\hline
\end{tabular}

dence, represents the level of tectonic activity of the region. Higher $n$ value shows that the regions manifest higher tectonic activity. Therefore, the study of variations of $Q_{0}$ and $n$ for different tectonic regions forms the basis of many studies as both these parameters are considered as important. From the comparative study of $n$ and $Q_{0}$ values (table 4) for Garhwal and Kumaun Himalayas it can be stated that Kumaun Himalayas are more heterogeneous and less stable as compared to the adjoining Garhwal Himalayas. Further, the comparison of Kumaun Himalayas with that of Koyana region and northeast India indicates that the Kumaun region is more heterogeneous compared to the Koyana region but less heterogeneous than northeast India. The estimation of $Q_{c}$ in Kumaun Himalaya region will be an important parameter for the assessment of seismic hazard in the region because $Q_{c}$ is considered as a measure of $Q_{\beta}$ (attenuation of $S$-waves) using $Q_{c} \approx Q_{\beta}$ given by Aki (1980).

\section{Conclusions}

The estimated $Q_{c}$-values, using $30 \mathrm{sec}$ coda window, vary from 65 to 283 at $1.5 \mathrm{~Hz}$ to 2119 to 3279 at $24.0 \mathrm{~Hz}$ and their mean values vary from 132 at $1.5 \mathrm{~Hz}$ to 2562 at $24.0 \mathrm{~Hz}$. This showed that $Q_{c}$-values are frequency dependent in the Kumaun Himalaya and their values increase as frequency increases. A frequency dependent $Q_{c}$ relationship, $Q_{c}=(92 \pm 4.73) f^{(1.07 \pm .023)}$, is obtained for the region. The relationship provides the average attenuation characteristics for the Kumaun Himalaya region.

The comparison of attenuation relationships of the four Indian regions i.e., the Garhwal Himalaya (Gupta et al 1995), Koyna, northeast India (Gupta 1999) and Kumaun Himalaya (present study) showed that all these regions manifest, by and large, similar attenuation relationships. 

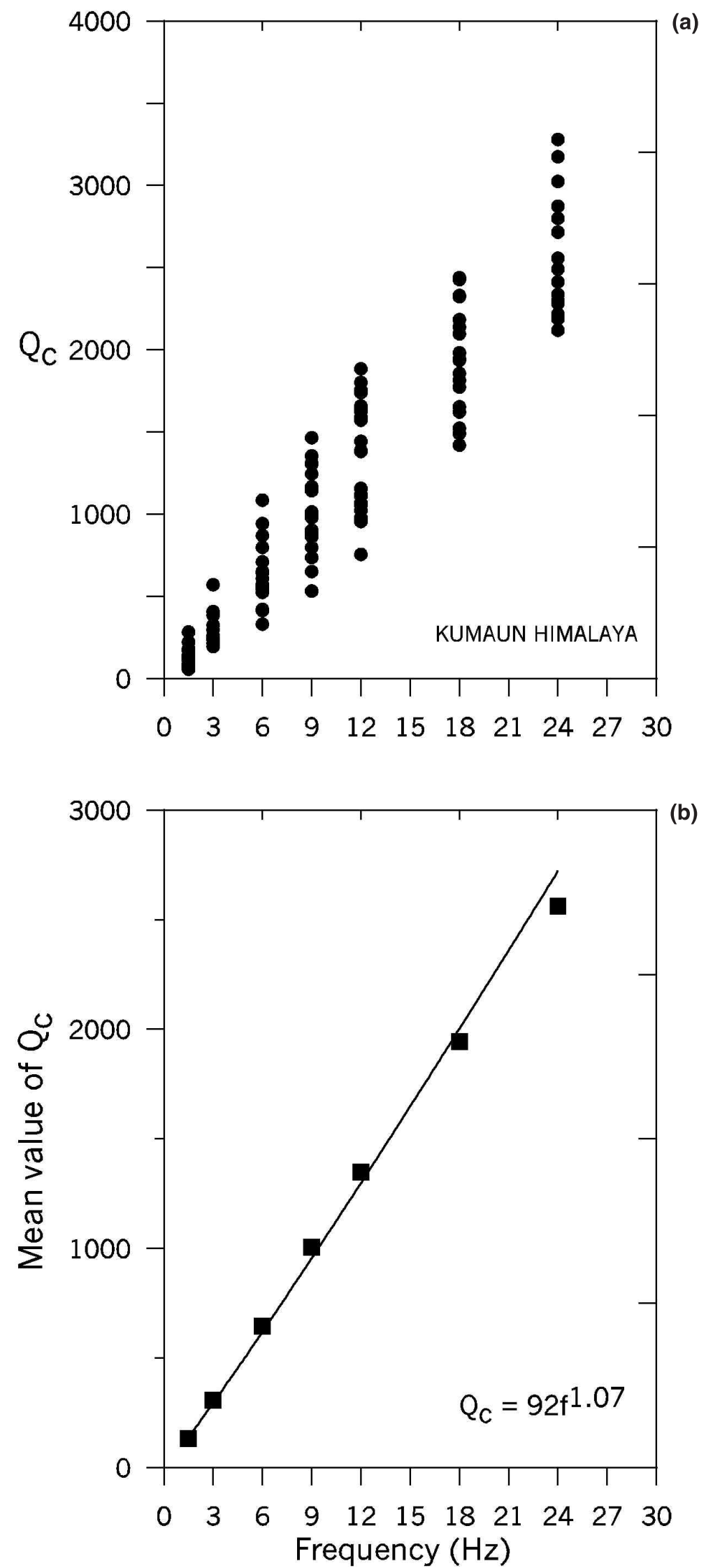

(b)

Figure 3. (a) Plot of estimates as a function of frequency and (b) Mean values of $Q_{c}$ as a function of frequency. A frequency dependent $Q_{c}$ relationship $Q_{c}=(92 \pm 4.73) f^{(1.07 \pm .023)}$ is obtained for the region. 
Table 3. Mean value of $Q_{c}$ computed from all the $Q_{c}$ estimates at each frequency. Standard error from mean and total number of observations $(N)$ are also given in the table.

\begin{tabular}{ccc}
\hline$f_{c}(\mathrm{~Hz})$ & $Q_{c}$ & $N$ \\
\hline 1.5 & $132 \pm 15.00$ & 16 \\
\hline 3.0 & $307 \pm 33.16$ & 11 \\
\hline 6.0 & $645 \pm 47.03$ & 17 \\
\hline 9.0 & $1005 \pm 58.27$ & 19 \\
\hline 12.0 & $1349 \pm 71.85$ & 22 \\
\hline 18.0 & $1944 \pm 76.70$ & 20 \\
\hline 24.0 & $2562 \pm 93.00$ & 16 \\
\hline
\end{tabular}

Table 4. Comparison of frequency dependent $Q_{c}$ relationships obtained using $30 \mathrm{sec}$ coda window of local earthquake data.

\begin{tabular}{lccc}
\hline Region & $Q_{0}$ & $n$ & $\begin{array}{c}\text { Attenuation } \\
\text { relationship }\end{array}$ \\
\hline Garhwal Himalaya & 110 & 1.02 & $Q_{c}=110 f^{1.02}$ \\
\hline Koyna region & 97 & 1.09 & $Q_{c}=97 f^{1.09}$ \\
\hline Kumaun Himalaya & 92 & 1.07 & $Q_{c}=92 f^{1.07}$ \\
\hline North East region & 86 & 1.02 & $Q_{c}=86 f^{1.02}$ \\
\hline
\end{tabular}

\section{Acknowledgement}

This work forms a part of a research project sponsored by the Department of Science and Technology, Seismology Division, Govt. of India, New Delhi. The generous financial support provided is thankfully acknowledged.

\section{References}

Aki K 1980 Scattering and attenuation of shear waves in the lithosphere; J. Geophys. Res. 85 6496-6504

Aki K and Chouet B 1975 Origin of the coda waves: source attenuation and scattering effects; J. Geophys. Res. 80 $3322-3342$

Gupta S C, Singh V N and Kumar A 1995 Attenuation of coda waves in the Garhwal Himalaya, India; Phys. Earth and Planet. Interiors 87 247-253

Gupta S C 1999 Seismic wave attenuation characteristics of three Indian regions; Ph.D. Thesis. University of Roorkee, Roorkee, pp. 200 (unpublished)

Malinconico Jr L L 1989 Crustal thickness estimates of the western Himalaya. In: Tectonics of the western Himalayas (eds) L L Malinconico Jr. and R J Lillie; Geol. Soc. Am. Spl. Paper 232 237-242

Molnar P and Tapponnier P 1975 Cenozoic tectonics of Asia: Effects of a continental collision; Science 189 419-426

Powell C Mc A 1979 A speculative tectonic history of Pakistan and surroundings: Some constraints from Indian Ocean. In: Geodynamics of Pakistan, (eds) A Farah and K A DeJong, Geological Survey of Pakistan 5-24

Pulli J J 1984 Attenuation of coda waves in New England; Bull. Seismol. Soc. Am. 74 1149-1166

Rautian T G and Khalturin V I 1978 The use of the coda for the determination of the earthquake source spectrum; Bull. Seismol. Soc. Am. 68 923-948

Roecker S W, Tucker B, King J and Hatzfield D 1982 Estimates of $Q$ in central Asia as a function of frequency and depth using the coda of locally recorded earthquakes; Bull. Seismol. Soc. Am. 72 129-149

Valdiya K S 1995 Proterozoic sedimentation and Pan African geodynamic development in Himalaya; Precambrian Research $\mathbf{7 4} 35-55$

Valdiya K S 1999 Fast uplift and geomorphic development of the western Himalaya in Quaternary period. In: Geodynamics of NW Himalaya Gondwana Research Group Memoir (eds) A K Jain and Manickvasagam 6 179187

Woodgold C R D 1994 Coda Q in the Charlevoix, Quebec, region: Lapse-time dependence and spatial and temporal comparison; Bull. Seismol. Soc. Am. 84 1123-1131 